
3
Research Square
Preprints are preliminary reports that have not undergone peer review.
They should not be considered conclusive, used to inform clinical practice, or referenced by the media as validated information.

\title{
The effect of concurrent mental illness on tuberculosis treatment outcomes at Butabika National Referral Mental Hospital - Uganda
}

Derrick Kimuli ( $\nabla$ derrickkimuli@gmail.com )

Management Sciences for Health https://orcid.org/0000-0002-5302-7077

Etwom Alfred

National Tuberculosis and Leprosy Program (NTLP)

Nicholas Sebuliba Kirirabwa

Management Sciences for Health

Racheal Tibyonza

Butabika National Mental Referral Hospital

Daniel Ayen Okello

Kampala Capital City Authority (KCCA)

\section{Brian Kibwika}

Cavendish University Uganda

Julie A. Wieland

Health Strategy Delivery Foundation (HSD)

Deus Lukoye

Management Sciences for Health

Research article

Keywords:

Posted Date: June 12th, 2019

DOI: https://doi.org/10.21203/rs.2.10222/v1

License: (c) (i) This work is licensed under a Creative Commons Attribution 4.0 International License. Read Full License 


\section{Abstract}

Background The renaissance of tuberculosis (TB) through certain groups of the population including patients with mental illness has been observed for the last 30 years. However, literature on treatment outcomes of patients with mental illness is still scarce. The following research examines the impact of concurrent mental health illness on TB treatment outcomes in Butabika National Referral Mental Hospital. Methods A retrospective analysis of data for registered TB patients with and without mentalillness for the period July 2013 to December 2015. Data was extracted for age, sex, human immunodeficiency virus (HIV) serostatus and Directly Observed Treatment (DOT) status, TB classification and history of TB treatment. For HIV co-infected patients, data on Co-trimoxazole preventative therapy (CPT) and anti-retroviral therapy (ART) uptake was collected. Treatment outcomes of patients with and without mental illness were analyzed. Results A total of 325 records were analyzed, of which 105 (32\%) patients were found to have had mental illness. Of the patients with mental illness, 61 (58\%) were HIV positive while of those without mental illness, 134 (61\%) were HIV positive. Patients with mental illness were less likely to complete treatment (adj. OR $0.3,95 \% \mathrm{Cl} 0.2-0.5, p=0.000$ ) more likely to die, (adj. OR $2.3,95 \% \mathrm{Cl} 1.2-4.3, \mathrm{p}=0.01$ ) and more likely to get lost to follow up during treatment (adj. OR 2.8, 95\% $\mathrm{Cl} 1.3-6.0, \mathrm{p}=0.005$ ) compared to those without mental illness. Conclusion Mental illness is associated with unfavorable outcomes of TB treatment. We recommend targeted interventions for patient follow up at this hospital and further studies to guide improvement in the quality care in this patient population. We also recommend psychosocial assessment and counselling for all patients on TB treatment as practice to improve treatment outcomes for all TB patients in Kampala.

\section{Background}

With approximately 450 million people currently affected by mental illness worldwide, psychiatric morbidity ranks among the world's leading causes of ill-health with one in four people likely to be affected at some point during their lifetime(1). On the other hand, tuberculosis (TB) remains the leading cause of death worldwide(2). During the last 30 years, an increase in the incidence of the TB (3)(4)(5)(6) was observed in certain groups of the population including the homeless (3), human immunodeficiency virus (HIV) infected (7), alcohol and drug abusers (8), and immigrants from countries where TB is endemic (9). Psychiatric patients not only possess one or more of such risk factor for TB (10)(11) but the psychological and social impact of being a TB patient has been demonstrated to affect compliance to TB treatment (12)(13). Furthermore, evidence demonstrates the importance of mental health before, during and after TB disease/treatment (14). Psychosocial issues (15) including stigma, isolation (16), a feeling of social neglect(17), helplessness (18), other psychological reactions to disclosure of TB disease (19) and medication side effects affect adherence to TB treatment. This scenario may be worsened by the length of treatment often required for cure.

Research has shown the existence of a positive and independent relationship between mental illness and TB(20) with some studies showing rates of mental illness of up to $70 \%$ among TB patients. The causal relationship between TB and mental illness however remains a complicated subject. Drug interactions 
between anti-psychotic and anti-TB drugs have been documented potentially affecting treatment adherence (21). Therefore close monitoring of treatment for common mental illness such as depression, the most common mental illness among TB patients,(8) could improve adherence to anti-TB treatment (22). Although tuberculosis is assumed to be over represented in patients with psychiatric illnesses (23) (24)(20)(18)(4), in a low resource setting like Uganda, information about the outcomes of TB patients initiated on treatment with comorbidity of mental illness is scarce. In Uganda, Butabika National Referral Mental Hospital is the only national referral mental health institution in the country. The hospital provides

also general medical services including TB in addition to care for psychiatric patients. The purpose of this study was to establish the differences in TB treatment outcomes between patients with and without mental illness initiated on TB treatment in Butabika National Referral Mental Hospital.

\section{Methods}

\section{Study design}

This study was a retrospective study where data was collected from the TB unit register of Butabika National Referral Mental Hospital. All patients initiated on TB treatment are recorded in this register regardless of their mental health status.

\section{Data Source}

All TB patient data from the unit register that were reported during the period of July 2013 to December, 2015 at the hospital were included in the study. Data was collected on key demographic characteristics such as age, sex, TB patient category (pulmonary bacteriologically confirmed (PBC), pulmonary clinically diagnosed (PCD) and extra pulmonary (EP)), the Directly Observed Therapy (DOT) status, and the treatment outcome of each patient. All patients in the unit TB register were considered for the analysis.

\section{Data management and Analysis}

Data was entered into an electronic TB register in excel (25) and exported to STATA version 12.1 for analysis (STATA) Descriptive statistics was applied using means, medians, inter-quartile ranges and frequencies. The Person's Chi-square test was used to evaluate the association between mental illness in general and specific mental illnesses with different TB treatment outcomes including cure, treatment success, death, loss to follow up, treatment failure and those un-evaluated, according to the unit TB register. Patients were classified as those with and those without mental illness and this study classified TB treatment outcomes as favorable or unfavorable. Patients with treatment outcomes as cure or treatment completed were classified having favorable treatment outcomes while those whose outcomes were death, treatment failure, loss to follow up, and un evaluated were classified otherwise. For the purposes of this study illnesses like schizophrenia and psychotic depression are defined as psychosis to differentiate these from other psychiatric illnesses (table 2 in the results section). 


\section{Results}

A total of 325 TB patient records were reviewed, out of which 105 (32.3\%) were patients with comorbidity of mental illness. Overall, a TB patient with mental illness had a 3-fold risk (Adj. OR 3.2, 95\% Cl 1.9 - 5.2, $p=0.000$ ) of having an unfavorable TB treatment outcome as compared to patients without mental illness.

The mean age of the patients was 32.4 (Standard Deviation, 12.6). Five percent (15/325) of the patients were children (aged 0-14yrs) and 2.5\% (8/325) were aged 60 years and above. Sixty-four percent $(209 / 325)$ of the patients were male. Fifty-two percent (169/325) of the patients were PCD TB patients, $37.8 \%$ (123/325) were PBC TB patients while 10.2\% (33/325) were EP TB patients. A total of 34 patients (11\%) were previously treated. Eighty-four percent (273/325) were on DOT for TB. The HIV seropositive were 130 (40\%). Ninety-six percent (125/130) of HIV positive patients were on CPT and 71.5\% (93/130) ART. Distribution of mental illness comorbidity by key patient characteristics is shown in table 1 below.

Comparison patient characteristic between the two groups showed that patients without mental illness are more likely to be bacteriologically confirmed $(p<0.001)$ and extra pulmonary $(p=0.03)$ as compared to patients with mental illness. Also, patients with mental illness having TB/HIV co infection are less likely to be initiated on ART as compared to the patients without mental illness $(p=0.01)$. Comparisons of other characteristics revealed no significant differences The majority of TB patients (42.9\%) with mental illness had major psychosis followed by drug dependence (17\%). Table 2 below illustrates the occurrence of unfavorable treatment outcomes for patients with a differential diagnosis of mental illness. In sum, patients with psychosis have a three-fold risk of having an unfavorable treatment outcome as compared to patients without mental illness. Patients diagnosed with epilepsy, however are less likely to have an unfavorable treatment outcome, (Adj. OR $0.395 \% \mathrm{Cl}$ 0.1-0.9 $p=0.04$ ).

Analysis of individual treatment outcomes with mental illness revealed an association between mental illness and death while on TB treatment (adj. OR 2.3 (95\% Cl 1.2-4.3 $p=0.01$ ), loss to follow up (Adj. OR 2.8, 95\% Cl 13-6.1, $p=0.005$ ) and being un-evaluated (adj. OR 2.9, 95\% Cl 1.0-8.0 $p=0.04$ ). Patients with mental illness with TB/HIV co infection had a 3-fold risk of death while on TB treatment, see table 3 below.

\section{Discussion}

This study represents the first of its kind exploring TB treatment outcomes among patients with mental illness in Butabika National Referral Mental Hospital and nationally. The results are consistent with the limited existing literature. Our study showed a higher risk of death (especially among HIV co-infected patients), loss to follow up and not being evaluated at the end of treatment among patients with mental illness treated for TB compared their mentally healthy counterparts. Also, the percentage of patients that died of $14 \%$ and $27 \%$ among for all patients and HIV co-infected respectively was higher the overall performance of the district performance of $10 \%$ on this indicator (KCCA annual report 2014/2015). It can 
be speculated the higher death rate among TB patients with mental illness is a result of drug interactions(26). There have also been documented challenges in achieving anti-TB treatment compliance among patients with mental illness or among patients with substance abuse(21). The study also showed a 3- fold risk of loss to follow up among TB patients with mental illness. Challenges of non-adherence to TB treatment for patients on psychotherapy have been previously documented (27) (28). In a study of tuberculosis patients in Nigeria, $30.2 \%$ had a diagnosable mental disorder had not been established by the clinic staff (29) which may have contributed to poor or non-adherence to TB treatment. In order to minimize risks of non-adherence, clinic staff involved in management of TB patients with mental illness including those in settings not established for care for mental illness should develop a high index of suspicion to identify psychosocial disorders among patients to improve the quality of care. Although some patients were not evaluated after treatment for their outcomes, this finding was not associated with mental illness which for purposes of our study can be attributed to the very small number of patients in with this outcome.

This study demonstrated drug dependence ranked second among the mental illnesses and contributed markedly to the unfavorable treatment outcomes. Literature has shown that better TB treatment outcomes are achieved if efforts aimed at improving diagnosis of alcohol and substance abuse are undertaken to treat both concurrently (30)(31). It is worth noting that patients with a diagnosis of epilepsy on TB treatment had favorable treatment outcomes, similar to TB patients with no mental illness, compared to patients with other mental illnesses, just as TB patients with no mental illness at all. This might imply that factors that lead to unfavorable treatment outcomes in other patients with mental illness may not necessarily apply to patients with epilepsy. Although this study thoroughly explored treatment outcomes in patients with mental illness, we found mental illness was more common among the PCD TB patients than among the PBC and EP TB cases. We can attribute this finding to communication failure of the clinic staff to the patients with mental illness to collect sputum sample or the samples collected might not be of the sufficient quality or quantity hence disregarded by the laboratory personnel for analysis. However, this is beyond the scope of our report and may require further exploration.

Our study had limitations. It was conducted at the national mental health referral hospital where patients with severe mental illnesses are managed. Most of the patients analyzed therefore suffered from psychosis differing from studies done in other settings. Our results might therefore be biased towards patients with major mental illnesses. Although we found a high death rate, it was not possible to establish the cause e.g drug interactions, severe disease, trauma, assault), hence the need for prospective studies in this population. Given the retrospective nature of the study we could also not establish factors responsible for other unfavorable treatment outcomes such as loss to follow up or being unevaluated which may require other study designs. Poor social environment, lack of food and being homeless play a major role in failure to comply with TB treatment which this study was not able to assess further.

\section{Conclusion}


Mental illness is associated with unfavorable treatment outcomes of TB patients. There is a need to apply targeted interventions to improve the quality of TB care in this population to mitigate the risks of death and TB drug resistance. We recommend further studies to improve the understanding of the possible biological and social factors responsible for these outcomes, as well as addressing the knowledge gap in provision of quality care for patients with mental illness treated for TB.

\section{Declarations}

\section{Ethical considerations.}

The study received approval from Kampala Capital City Authority (KCCA) to provide an informative review of routinely collected data from Butabika National Referral Mental Hospital management as part of urban TB control activities. The study did not involve use of any patient identifiers.

\section{Consent to publish}

Not Applicable

\section{Availability of data and materials}

The dataset used and/or analyzed during the current study is available from the corresponding author on reasonable request.

\section{Competing interests}

The authors declare no competing interests.

\section{Funding}

This work did not receive any external funding.

\section{Author contributions}

DK generated the idea. DK and DL and wrote the paper. DK, and RT collected the data, AE, DK, and NSK analyzed the data. NSK, AE, DAO, BK and JAW reviewed the document. JAW edited the paper. All authors approved the paper for publication in a peer review journal. DL provided technical review for the paper. 


\section{Acknowledgements.}

We are grateful for the administrative and technical support provided by the management and staff of Butabika National Referral Mental Hospital who collected that data for this study. We also recognize the contribution of the patients whose records were used for analysis. The views expressed in this paper are solely those of the authors may not in any way represent the views of the institutions they are affiliated to.

\section{List Of Abbreviations}

CPT Co-trimoxazole preventative therapy

\section{ART Anti-retroviral therapy}

DOT Directly Observed Treatment

HIV Human Immune-deficiency Virus

KCCA Kampala Capital City Authority

EP Extra pulmonary

ICF Intensified Case Finding

LTBI Latent tuberculosis infection

NTLP National Tuberculosis and Leprosy Program

PCD Pulmonary clinically diagnosed

PBC Pulmonary bacteriologically confirmed

\section{TB Tuberculosis}




\section{WHO World Health Organization}

\section{References}

1. Weltgesundheitsorganisation, editor. Mental health: new understanding, new hope. repr. Geneva: World Health Organization; 2002. 178 p. (The world health report).

2. Tuberculosis Fact Sheet [Internet]. World Health Organization (WHO); 2016. Available from: http://www.who.int/mediacentre/factsheets/fs104/en/

3. Grange JM, Zumla A. Paradox of the global emergency of tuberculosis. The Lancet. 1999 Mar;353(9157):996.

4. Saez H, Valencia E, Conover S, Susser E. Tuberculosis and HIV among mentally ill men in a New York City shelter. Am J Public Health. 1996 Sep;86(9):1318-9.

5. Frieden TR, Fujiwara PI, Washko RM, Hamburg MA. Tuberculosis in New York City - Turning the Tide. N Engl J Med. $1995 \mathrm{Jul}$ 27;333(4):229-33.

6. Alland D, Kalkut GE, Moss AR, McAdam RA, Hahn JA, Bosworth W, et al. Transmission of Tuberculosis in New York City -- An Analysis by DNA Fingerprinting and Conventional Epidemiologic Methods. N Engl J Med. 1994 Jun 16;330(24):1710-6.

7. Theuer CP, Hopewell PC, Elias D, Schecter GF, Rutherford GW, Chaisson RE. Human immunodeficiency virus infection in tuberculosis patients. J Infect Dis. 1990 Jul;162(1):8-12.

8. Friedman LN, Sullivan GM, Bevilaqua RP, Loscos R. Tuberculosis Screening in Alcoholics and Drug Addicts. Am Rev Respir Dis. 1987 Nov;136(5):1188-93.

9. McKenna MT, McCray E, Onorato I. The Epidemiology of Tuberculosis among Foreign-Born Persons in the United States, 1986 to 1993. N Engl J Med. 1995 Apr 20;332(16):1071-6.

10. Lopez AG. Tuberculosis and the severely mentally ill. Am J Psychiatry. 1994 Jan;151(1):151-2.

11. Tuberculosis infection among people with severe mental illness. Psychiatr Serv. 1997 Jun;48(6):8335 .

12. Cremers AL, de Laat MM, Kapata N, Gerrets R, Klipstein-Grobusch K, Grobusch MP. Assessing the Consequences of Stigma for Tuberculosis Patients in Urban Zambia. Kumar A, editor. PLOS ONE. 2015 Mar 25;10(3):e0119861.

13. Mathew AS, Takalkar AM. Living with Tuberculosis: The Myths and the Stigma from the Indian Perspective. Clin Infect Dis. 2007 Nov 1;45(9):1247-1247. 
14. Verma A, Tripathi A, Mishra M, Verma S, Chaudhri S, Bansal A, et al. Impact of psychiatric profile and personality trait on directly observed tuberculosis treatment outcome. Int $\mathrm{J}$ Med Public Health. 2013;3(4):303.

15. Kelly P. Isolation and Stigma: The Experience of Patients With Active Tuberculosis. J Community Health Nurs. 1999 Dec;16(4):233-41.

16. T. R. Ndoro. Attitudes and perceptions towards TB in Grahamstown East in a time of HIV/AIDSA [M.S. thesis of Commerce in Organizational Psychology],. 2009.

17. Munro SA, Lewin SA, Smith HJ, Engel ME, Fretheim A, Volmink J. Patient Adherence to Tuberculosis Treatment: A Systematic Review of Qualitative Research. Rylko-Bauer B, editor. PLoS Med. 2007 Jul 24;4(7):e238.

18. Naidoo P, Mwaba K. Helplessness, Depression, and Social Support Among People Being Treated for Tuberculosis in South Africa. Soc Behav Personal Int J. 2010 Nov 1;38(10):1323-33.

19. U. Eram, I. A. Khan, Z. Tamanna, Z. Khan, N. Khaliq, A. J. Abid. Patient perception of illness and initial reaction to the diagnosis of tuberculosis. Indian J Community Med. 2006 Sep;31(3):198.

20. Araújo GS de, Pereira SM, Santos DN dos, Marinho JM, Rodrigues LC, Barreto ML. Common Mental Disorders Associated with Tuberculosis: A Matched Case-Control Study. Cardona P-J, editor. PLoS ONE. 2014 Jun 17;9(6):e99551.

21. Doherty AM, Kelly J, McDonald C, O'Dywer AM, Keane J, Cooney J. A review of the interplay between tuberculosis and mental health. Gen Hosp Psychiatry. 2013 Jul;35(4):398-406.

22. Pachi A, Bratis D, Moussas G, Tselebis A. Psychiatric Morbidity and Other Factors Affecting Treatment Adherence in Pulmonary Tuberculosis Patients. Tuberc Res Treat. 2013;2013:1-37.

23. Kehbila J, Ekabe CJ, Aminde LN, Noubiap JJN, Fon PN, Monekosso GL. Prevalence and correlates of depressive symptoms in adult patients with pulmonary tuberculosis in the Southwest Region of Cameroon. Infect Dis Poverty [Internet]. 2016 Dec [cited 2017 Jan 27];5(1). Available from: http://idpjournal.biomedcentral.com/articles/10.1186/s40249-016-0145-6

24. Deribew A, Tesfaye M, Hailmichael Y, Apers L, Abebe G, Duchateau L, et al. Common mental disorders in TB/HIV co-infected patients in Ethiopia. BMC Infect Dis [Internet]. 2010 Dec [cited 2017 Jan 27];10(1). Available from: http://bmcinfectdis.biomedcentral.com/articles/10.1186/1471-2334-10-201

25. Etwom A, Lukoye, Deus, Kimuli, Derrick, Mutesasira, Kenneth, Ruhweza, Martin, Pedro G, Suarez. Using electronic data management system leads to improved TB patient monitoring in Kampala, Uganda. 46th World Conf Lung Health Int Union Tuberc Lung Dis Union. 2015 Dec;19(12):S-562. 
26. Pai M-S, Yang S-N, Shiah I-S. Rifampin-zotepine interaction reduces effectiveness of antipsychotic drugs in a stable schizophrenia patient: Letters to the Editor. Psychiatry Clin Neurosci. 2012 Oct; 66(6):538-538.

27. Bosley CM, Corden ZM, Rees PJ, Cochrane GM. Psychological factors associated with use of home nebulized therapy for COPD. Eur Respir J. 1996 Nov;9(11):2346-50.

28. Kolbe J. Asthma education, action plans, psychosocial issues and adherence. Can Respir J. 1999 Jun;6(3):273-80.

29. Aghanwa HS, Erhabor GE. Demographic/socioeconomic factors in mental disorders associated with tuberculosis in southwest Nigeria. J Psychosom Res. 1998 Oct;45(4):353-60.

30. Pevzner ES, Robison S, Donovan J, Allis D, Spitters C, Friedman R, et al. Tuberculosis Transmission and Use of Methamphetamines in Snohomish County, WA, 1991-2006. Am J Public Health. 2010 Dec;100(12):2481-6.

31. Greenfield SF, Shields A, Connery HS, Livchits V, Yanov SA, Lastimoso CS, et al. Integrated Management of Physician-delivered Alcohol Care for Tuberculosis Patients: Design and Implementation. Alcohol Clin Exp Res. 2010 Feb;34(2):317-30. 